\title{
On the Experience Ecosystem, Drama, Choreography...
}

Jon: This issue clearly demonstrates a shift in thinking for practicing designers. Creators of physical, digital, and systematic products are moving away from the development of single, static things and are now considering the larger ecosystem of the experience in which these things are used. This experience lifecycle has even touched on children's toys, as described by Allison Druin; it is no longer enough to offer products with a narrow focus. Instead, practitioners must "design" the physical artifact, the digital artifact, the system of integration, the unboxing experience, and must even consider the urban fabric and culture in which the design is used.

It seems like few, if any, large corporations are organized in a way that supports this tremendous undertaking; the actual experience offering from these corporations is so watered down by the time it makes it to market that all indications of cohesion are lost.

Richard: Years ago I had the good fortune of working at Studio Archetype and Viant, where the focus was on helping clients figure out what to do as much as designing how to do something. Indeed, the Studio's founder, Clement Mok, wrote a book entitled Designing Business back then, and Viant's primary focus was on developing digital business strategy.

So, the approach to user research that I developed for both companies somewhat naturally looked at the larger ecosystem of the user experience, since that increased our contribution to figuring out what a business should do and facilitated designers' contribution to the same.
Companies that involve user experience research and design in their business in such ways have a better chance of effectively considering and addressing that bigger picture. Secil Watson wrote of taking such an approach at Wells Fargo in our January+February 2008 issue. But it is hard to pull that off.

You attended Interaction 08 in February. Did any of the presenters provide guidance about this?

Jon: Absolutely. Chris Conley of Gravity Tank described to a packed room how dramatic features can be integrated in interaction design solutions in order to provide for stronger and more engaging experiences. His talk introduced words that might be familiar to industrial designers-like anthropomorphism-to a group of interaction practitioners. His talk also illustrated how an emphasis on emotion in the fourth dimension can create jarring, and often rich, responses.

I think he hit the nail on the head as he made multiple comparisons between our respective industries and the animated film industry. As he described, these filmmakers "don't do email and meetings; they work on the film for six years. And with each film, they build a billion-dollar business."

Chris's pragmatic takeaway is to consider the emotional resonance of the designed artifact over time and include hooks that include a glimmer of drama or engagement. His managerial takeaway, however, is even more important: Spend more time creating and less time explaining, facilitating,

(continued on page 79) 


\section{INTERACTIONS CAFE}

(continued from page 80)

shepherding, discussing, or arguing. Ultimately, his points indicate yet another convergence of worlds-in this case, one where the more entertainment-based worlds of movies, plays, and theater are beginning to intrude on more traditional interaction design solutions. This seems to offer some fairly explicit, new, and rich techniques for us to exploit in "designing the ecosystem."

Richard: "Dancing in the Streets" offers excellent lessons along these lines. Because the installation was intended to be experienced, Scott Palmer and Sita Popat designed and developed it with others largely by using and experiencing it. But that was all done in careful consideration of the setting, including its history, and via the application of their performance skills and their extensive, relevant research.

Jon: In a roundabout way, I think what we are both describing is a way for our pragmatic day-today work to address the "bigger picture." Whether we approach this by referencing dance, architecture, and narrative or by alluding to history and context, or by looking at the end-to-end experience lifecycle, we can imbue an essence of richness into our work that will have a more human resonance. Perhaps this is the actionable message in Richard Seymour's cover story: By finding ways to integrate cultural hooks into our work, we can allow our work to have a more permanent and appropriate place in the world around us.

-Richard Anderson and Jon Kolko

DOI $10.1145 / 1353782.1353833$

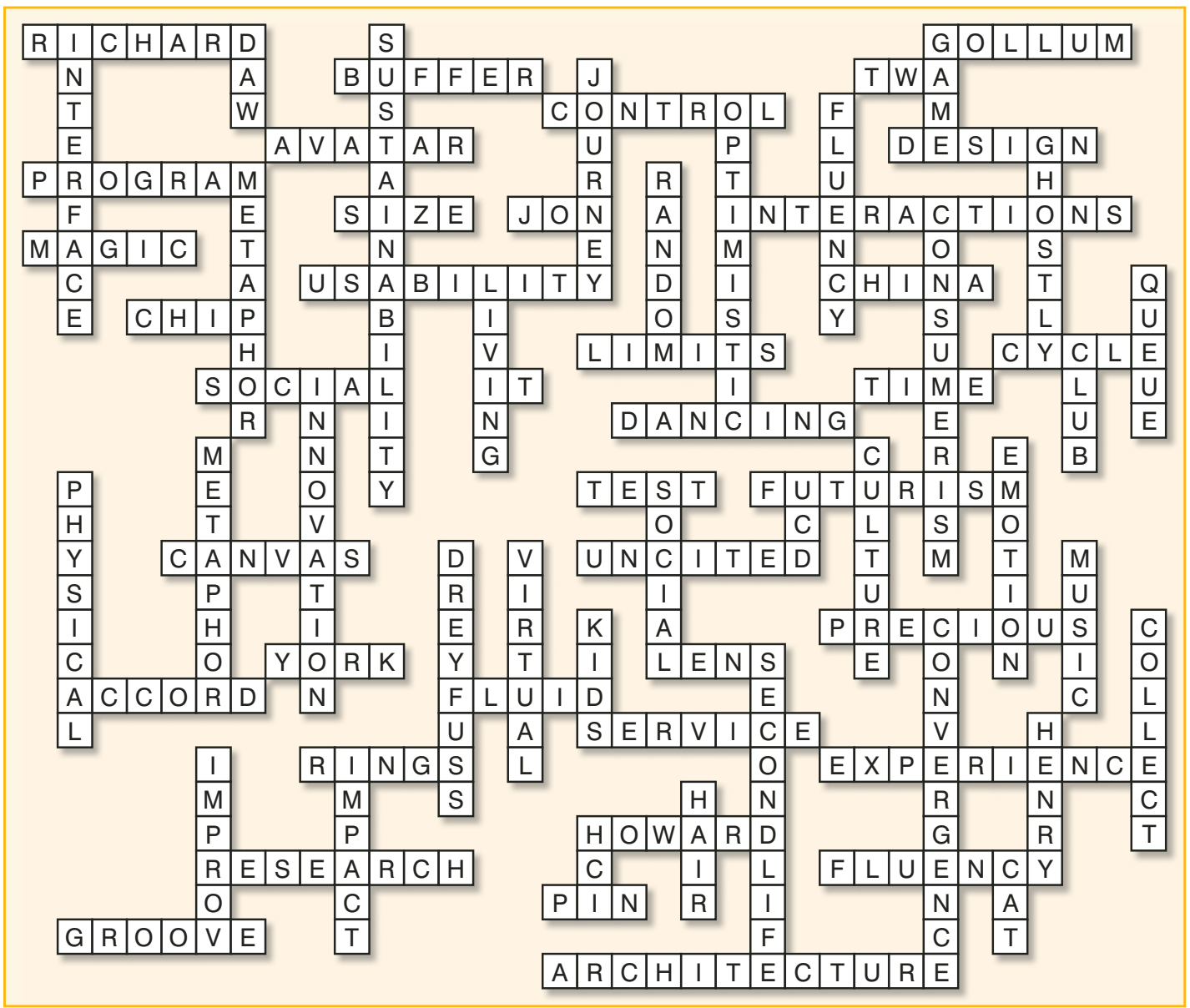

